\section{Desert ecosystems}

Arid-Land Ecosystems: Structure, Functioning and Management. Volume 1. Edited by D.W. Goodall, R.A. Perry and K.M.W. Howes. Pp. 881. (Cambridge University Press: Cambridge, 1979.) $£ 45$.

THIS volume is one of two that will give an overall account of arid-land studies, one of the themes of the International Biological Programme. Although much of the official IBP work was carried out in the USA, a considerable amount of countries at the same time, and much of this information has also been included. the editors, it has not proved possible to provide global coverage of arid regions. There is no account of South American deserts and the Sudan, a country with one of the largest desert areas, is only mentioned in passing. However, the areas that are described include North America, northern Africa, southern Africa, Australia, and South-West and Central Asia. The climate, soils, geomorphology, hydrology, flora and fauna are covered and the processes that operate within, and component, atmospheric, soil, plant and animal processes.

The editors' task must have been a nightmare for in spite of international cooperation investigators still seem to have operated within their own sub-set of published work and conventions, often set by linguistic or old colonial spheres of similar work was also carried out in other Unfortunately, and in spite of efforts by control, the ecosystem are dealt with under influence. This can give rise to reliance on a very distorted range of literature or undue emphasis on a personal field of interest in a review article. Thus, one regional account emphasises productivity, another phytosociology, and in some accounts animals receive scant attention. The characterisation of regional climate is similarly diversely treated. In one account simplified 'Walter Klimadiagramm' are given, another resorts to rainfall tables, a third makes use of maps with isohyets, and others give the 'Walter Klimadiagramm' in full. Standardisation of representation would have allowed comparison and integration to be made more easily.

The part of the volume devoted to processes is more satisfactory and includes an excellent chapter on diversity and niche structure in desert communities by E.R. Pianka. Chapters on radiation, precipitation and soil processes deal well with specifically desert conditions. Other chapters treat topics more generally.

This book has not managed to distil the knowledge accumulated in the IBP studies on arid ecosystem structure and function in a unified way. It would be unfair, however, to be too critical as it is difficult to give constructive suggestions on how a more satisfactory account could have been achieved. It is perhaps best to accept the volume for what it is - a mammoth compendium of information on many of the world's desert ecosystems.

\section{J. Chadwick}

M. J. Chadwick is Senior Lecturer in Ecology at the University of York, UK.

although gestation lengths are given in three of the chapters and Martin and Charles-Dominque's basic decoding of home range and social structure in nocturnal forms enters at least three others. One might quibble that social structure of the diurnal species is underrepresented, but this has been dealt with in recent books by A.F. Richard (Behavioural Variation: Case Study of a Malagasy Lemur; Bucknell University Press, Lewisburg; Associated University Presses, London, 1978 and edited by I. Tattersall and R.W. Sussman (Lemur Biology; Plenum, New York, 1975).

Chapters cover classification (J-J. Petter and A. Petter-Rouksseaux), phylogenetic and allometric aspects of behaviour (R.D. Martin), reproduction (R.N. Van Horn and G.G. Eaton), maternal behaviour (P.H. Klopfer and K.J. Boskoff), development (G.A. Doyle), learning (B.J. Wilkerson and D.M. Rumbaugh), vocal communication (J-J. Petter and C.M. Hladik), diet (C.M. Hladik), spatial distribution (J.I. Pollock), vision (G. Pariente), olfaction (A. Schilling), locomotion (A. Walker), field studies of lorisids

(P. Charles-Dominque and S.K. Bearder), and a study of Tarsius bancanus (C. Niemitz).

One theme which runs through the book is the importance of nocturnal life, where the prosimians may give us clues to our common ancestor. Charles-Dominique argues that small diurnal primates would compete with diurnal birds, which explains why small primates are nocturnal, and only larger ones diurnal. This size constraint then reappears in Doyle's and Martin's treatments of allometry in brain size and developmental rates.

The reader may trace his own interests. One such might be the "psychology of place". Wilson and Rumbaugh stress that prosimians approach formal learning tests by position, not by attention to objects. Then Charles-Dominique remarks that rainforest galagos and pottos can be trapped twice running if the trap is moved to a nearby site, for "It would seem the traumatic effect of capture is associated more with the place . . . then with the trap itself"'. Schilling then shows how scentmarking identifies places in both individual and social contexts - again, the recourse of a more nocturnal, less visually oriented evolutionary lineage. This, in turn, ties in with the views of Pollock, Bearder, and Charles-Dominque on ranging, "detour problems" for slow-climbing forms in the forest canopy, and social organisation by the overlapping of home ranges. For many prosimians, social life itself depends on position in the forest, cued by scent marks, rather than on vocal or visual contact with other animals.

One notable contribution is Georges Pariente's study of prosimian vision. Pariente presents photography of the living retina, electrophysiological studies, measurements of light intensity in Madagascar forest conditions, and activity of nocturnal species in relation to ambient light. He argues that "nocturnal life is more a shift in thresholds of sensitivity than a completely new, 'inversed' mode of existence. The notion of 1 night when vision is impossible only exists for strict diurnal species ... Nocturnal prosimians can move around perfectly well in full daylight, using their vision in the usual way". He concludes that if the prosimian eye retains this degree of plasticity, one might propose a "primate ancestor which needed to see wellby both day and night . . . small bodies, perhaps arboreal, with an appreciable amount of activity in the daytime . . . This ancestral form would have already been able to decode both in the intensity and frequency of light".

It is wholly appropriate that The Study of Prosimian Behaviour is dedicated to Georges Parente, who was tragically killed in a traffic accident shortly after completing his article for this book.

Alison Jolly prosimian behaviour.

The editors are to be congratulated on assembling articles of fairly standard format, with a minimum of repetition, Sussex, Brighton, UK. 